\title{
LAS FORMAS DE DELIBERACIÓN ENVUELTAS EN LA BIOÉTICA: LA DELIBERACIÓN TÉCNICA Y LA ÉTICO-MORAL
}

Gerson Neves Pinto*

Fecha de recibido: 14 de noviembre de 2013.

Fecha de aprobado: 13 de marzo de 2014.

Artículo de Reflexión

Forma de citación: Neves, G. (2014). Las formas de deliberación envueltas en la Bioética: la deliberación técnica y la ético-moral. Revista Prolegómenos. Derechos y Valores, 17, 33, 15-26.

\begin{abstract}
Resumen
En este artículo, se analiza la formulación del problema acerca de las nuevas tecnologías y de sus límites éticos y jurídicos. Por lo tanto, en un primer momento se evalúan las contribuciones de dos de los más importantes jus-filósofos contemporáneos sobre el tema, Jürgen Habermas y Ronald Dworkin, y un posible diálogo de estos dos últimos con aquél que fue uno de los fundadores de la ética clásica, Aristóteles. Posteriormente, intentamos responder a la cuestión de ćcómo podríamos comprender esa idea que Dworkin denomina «dislocamiento moral» entre el azar y elección o como lo denomina Habermas la «ampliación de contingencia»? Finalmente, se analiza cómo la distinción aristotélica entre deliberación técnica y la deliberación ético-moral puede colaborar para una mejor comprensión de las cuestiones acerca de las decisiones y elecciones a hacer por los agentes morales (como pacientes, familiares o jueces) y el tipo de deliberación técnica hecha por el médico y el profesional sanitario.
\end{abstract}

Palabras-clave:

Ética, bioética, genética, contingencia y principios.

\section{THE DELIBERATION METHODS INVOLVED IN BIOETHICS: THE TECHNICAL AND THE ETHICAL-MORAL DELIBERATION}

\begin{abstract}
This article analyses the problem formulation regarding new technologies and their ethical and legal limits. Therefore, in first place it assesses the contributions of two of the most important contemporary jus-philosophers on the topic, Jürgen Habermas and Ronald Dworkin, and a possible dialog of these two with the one who was one of the founders
\end{abstract}

* Doutor en Filosofía por la École Pratique des Hautes Études- Sorbonne- Paris, Mestre en Filosofía por la UFRGS y Professor Adjunto de Filosofía del Derecho en la Universidade do Vale do Rio dos Sinos, RS, Brasil. Dirección postal: Rua Luiz Afonso, 600/202, Porto Alegre, RS, Brasil. Dirección de correo electronico: gerson.p@terra.com.br 
of the classical ethics, Aristotle. Subsequently, it tries to answer the question of how can we understand the idea that Dworkin called "moral dislocation" between chance and choice or what Habermas called "expanded contingency"? Finally, it discusses how the Aristotelian distinction between technical and ethical-moral deliberation can collaborate to form a better understanding of the issues concerning the decisions and choices to make by moral agents (such as patients, family members or judges) and the type of technical deliberation done by the doctor and the healthcare professional.

\title{
Keywords:
}

Ethics, bioethics, genetics, contingency, principles.

\section{OS MÉTODOS DE DELIBERAÇÃO ENVOLVIDOS EM BIOÉTICA: A TÉCNICA EA DELIBERAÇÃO ÉTICO-MORAL}

\begin{abstract}
Resumo
Este artigo analisa a formulação de problema em relação a novas tecnologias e seus limites éticos e legais. Portanto, em primeiro lugar, avalia as contribuições de dois dos mais importantes contemporânea jus-filósofos sobre o tema, Jürgen Habermas e Ronald Dworkin, e um possível diálogo desses dois com aquele que foi um dos fundadores da ética clássica, Aristóteles. Posteriormente, ele tenta responder à questão de como podemos entender a idéia de que Dworkin chamou de "deslocamento moral" entre o acaso ea escolha ou o que Habermas chamou de "contingência expandido"? Finalmente, discute-se como a distinção aristotélica entre técnica e deliberação éticomoral pode colaborar para formar uma melhor compreensão das questões relacionadas com as decisões e escolhas a fazer pelos agentes morais (como pacientes, familiares ou juízes) eo tipo de técnica deliberação feito pelo médico eo profissional de saúde
\end{abstract}

\section{Palavras-chave:}

Ética, Bioética, Genética, Contingência, Princípios.

\section{INTRODUCCIÓN}

En su libro El futuro de la naturaleza humana, ¿hacia una eugenesia liberal? el filósofo Habermas presenta un argumento contra lo que se convino denominar de eugenesia liberal, y por tanto, recurre a este tipo de argumento basándose en una tesis defendida por Ronald Dworkin en Virtud soberana, en la que se afirma que los recientes avances en el campo de ingeniería genética ocasionarán un cambio en el límite entre el azar y la elección. El cambio en este límite podría ocasionar, según Dworkin, el colapso de elementos centrales de nuestra moralidad convencional, en otras palabras, podría llevar a una situación de caída libre moral. O dicho de otra forma, como podríamos comprender esta idea que Dworkin denomina «dislocamiento moral» entre el azar y la elección o como Habermas denomina la «ampliación de contingencia».

Podemos entender estas dos expresiones indicadoras de una crisis de valores, de tradición ético-moral occidental, para tratar de comprender las cuestiones y problemas traídos por los rápidos cambios en la ciencia, los cuales hoy son objeto de reflexión de la bioética, y sus aplicaciones en 
los diagnósticos, pronósticos y terapias médicas. Este nuevo horizonte nos pone delante de una desafiante reformulación de problemas morales, jurídicos y políticos que el avance de estas nuevas tecnologías producirá en un futuro bien próximo. Para Dworkin es eso que significa «Jugar a ser Dios»; no el miedo de hacer algo errado, pero sí el de perder la capacidad de distinguir entre lo cierto y lo errado.

Dworkin sostiene que estas innovaciones y modificaciones en técnicas genéticas son capaces de alterar las bases de la experiencia moral de la sociedad. La ética, la moral y el derecho, a partir de este nuevo cuadro situacional de nuevas tecnologías, tienen que formular nuevos límites y protecciones jurídicas en la regulación, producción y utilización de estas innovaciones.

Para tratar de responder a esta cuestión sobre la diferencia fundamental entre el grado de responsabilidad del agente en sus acciones y aquello que nos es dado como pantalla de fondo de nuestro actuar, Dworkin nos indica que tenemos, de un lado, los seres naturales que poseen un cierto código interno y, de otro, lo que siempre hacemos o deliberamos, con una tenue línea divisoria, esto es, el límite entre lo que no se puede deliberar (lo que es por naturaleza o por azar) y lo que es pasible de modificación y deliberación (elección).

Los descubrimientos de la ingeniería genética pasaron a dominar este saber, o sea, aquello que antes era tenido como «natural», hoy es perfectamente factible de interferencia humana, para bien o para mal. Sin embargo, debemos hacer una distinción crucial entre este tipo de deliberación que se verifica en el actuar humano y en la deliberación técnica. Esta última encuentra en la técnica utilizada por el médico un buen ejemplo. Pero, ¿cuál es la diferencia entre estos dos tipos de deliberaciones?

Para que podamos comprender esta distinción, pretendemos mostrar en las próximas páginas lo que en la Ética Nicomáquea de Aristóteles existe de similar entre estas dos deliberaciones $y$ en qué difieren ellas. Cuando en la Ética Nicomáquea Aristóteles describe el razonamiento práctico, no está pensando sólo en la ética sino, también, como él mismo señala, en la técnica, especialmente en aquélla que en su época se había convertido en paradigmática, la técnica médica, la medicina. Toda la teoría de la elección, de la deliberación, de la prudencia, del término medio, del razonamiento probable, la toma de decisiones en situación de incertidumbre, etc., se aplica por igual a la medicina y a la ética. La deliberación busca analizar los problemas en toda su complejidad. Eso supone ponderar tanto los principios y valores implicados como la circunstancia y las posibles consecuencias del caso. Esto permitirá conocer todos, o al menos, los más probables cursos de acción.

Al final, concluiremos que resulta claro que las decisiones en este campo transcienden el plano meramente técnico. Es una discusión relativa a los principales actores de esta escena: desde el médico, con su deliberación técnica, hasta el paciente, con su deliberación moral.

\section{LA INVENCIÓN DE LA BIOÉTICA}

Desde la creación del nombre Bio-Ethik, esta nueva disciplina encierra una ambigüedad fundamental: ella es, al mismo tiempo, antigua y moderna, pues decir "Ética» es evocar la genealogía del pensamiento occidental, donde es posible poner «al desnudo las estructuras del Occidente», como afirma el jurista Pierre Legendre (1985, p. 13). Por otro lado, ella es de facto postmoderna en aquello que investiga, pues su objeto de saber son las nuevas tecnologías que a través de investigaciones y experiencias prometen traer grandes beneficios al género humano. La noción de bioética que aparece solamente en la década de los años 70, del Siglo XX en los EE UU, reenvía, primeramente, a un conjunto de procedimientos y prácticas que ponían en duda los avances de las técnicas biomédicas. Como si el espacio entre la vida y la muerte, la salud y la enfermedad, el dolor y la esperanza, la anamnesis 
y el tratamiento dispensado al hombre por la ética médica no fuera más el mismo y no fueran las mismas nociones de la ética griega antigua las hoy utilizadas por la bioética. En fin, como nos recuerda Engelhardt: «El súbito surgimiento de la bioética es un enigma: ella vino aparentemente de la nada» (2003, p. 438).

Para intentar entender este enigma, Habermas nos recuerda que todos los avances en las técnicas e investigaciones constituyen una nueva especie de desafío, pues ellos modifican aquello que «somos por naturaleza» $y$, citando a Kant, Habermas afirma: «Lo que Kant todavía consideraba el "reino de la necesidad" se ha transformado desde la óptica de la teoría de la evolución en un "reino de la casualidad". Y ahora la técnica genética desplaza las fronteras entre esta base natural indisponible y el "reino de la libertad" » $(2002, \text { p. } 44)^{1}$.

Como afirmó el filósofo Habermas, las técnicas innovadoras provenientes de la genética dislocaron la frontera entre la base natural indisponible [aquello que es necesario, eterno o como el evolucionismo moderno denominó: el azar] y el llamado reino de la libertad (dominio del contingente). La intervención de las tecnologías en aquello que hasta entonces era absolutamente natural o por azar (fecundación, gestación, mutaciones, etc.) hizo que ocurriera una ampliación del ámbito de intervención del hombre en aquello que era «natural», modificando, así, la estructura general de nuestra experiencia moral.

Imaginemos un joven o una joven que reciba la noticia de que su patrimonio genético fue manipulado sin ninguna razón terapéutica. Y, de esta forma, percibe que sus padres realizaron esta intervención eugénica con la buena intención de mejorar las chances de la niña en el

1 Este texto de Habermas [El futuro de la naturaleza humana, ¿Hacia una eugenesia liberal?] se constituye en una versión reeditada de la conferencia Christian Wolff, impartida en la Universidad de Marburg el 28 de junio de 2001, que consideró la discusión sobre el tratamiento que se debe dar a las técnicas genéticas. futuro. Los padres, ciertamente, se dejaron llevar por sus propias preferencias. Ahora, no es nada cierto que la niña al crecer, haga suyas las representaciones y preferencias de sus padres. En este caso, si ella no se identifica con estas preferencias, esta irá a ponerla en duda, preguntándose por ejemplo, porqué sus padres le dotaron del don de las matemáticas en lugar de capacidades atléticas o musicales que serían mucho más útiles para la carrera de una deportista de alto nivel o de una pianista en que ella desea convertirse (Habermas, 2002, p. 109).

A esta modificación de nuestra experiencia moral, Habermas la llama «la destradicionalización de los mundos de la vida». En este punto, el posicionamiento de Habermas coincide con el de Dworkin ${ }^{2}$, pues lo que Habermas denomina «la destradicionalización de los mundos de la vida» (2002, p. 41), Dworkin lo llama «dislocamiento moral». Podemos entender estas dos expresiones como señalizadores de una crisis de los valores de la tradición ético-moral occidental para tratar y comprender las cuestiones y problemas traídos por los rápidos cambios en la ciencia, los cuales hoy son objeto de reflexión de la bioética, y sus aplicaciones en los diagnósticos, pronósticos y terapias médicas ${ }^{3}$. Este nuevo horizonte, nos pone frente a una desafiante reformulación de problemas morales, jurídicos y políticos que el avance de estas nuevas tecnologías producirá en un futuro bien cercano.

En esta línea esencial establecida entre el azar (o su versión teológica: Dios) y lo que nosotros podemos realizar con el patrimonio por el cual somos responsables, encontramos lo que Dworkin considera la base de nuestra ética y de nuestra moralidad, él afirma: «El límite capital entre azar y elección constituye la columna

2 Aunque sostengan posiciones antagónicas, en cierto sentido, Dworkin y Habermas también tienen muchos puntos en común, de los cuales solamente hago referencia a algunos.

3 Michael Sandel en su último libro The Case Against Perfection: Ethics in the Age of Genetic Engineering, pág. 9. llama a esta revolución genómica de «moral vértigo». 
vertebral de nuestra ética, y todo cambio significativo en ese límite provoca una seria distensión. Nuestro sentido de una vida bien vivida, por ejemplo, está fundamentalmente permeado por los supuestos arraigados sobre los límites superiores del breve tiempo de la vida humana»(2003, p. 488.)

Destaca, el autor, que delante de temas tan intensos y frente a innovaciones científicas que acarrean cambios, se modifican los valores de un extremo para otro. De este modo, un período de estabilidad moral fue sustituido por la inseguridad moral, lo que hizo que las personas recurrieran al término "Jugar a ser Dios», para designar el hecho de los científicos desvelar y dominar elementos de la ciencia que confieren poder sobre la naturaleza, ultrapasando el límite de lo que es (o fue) considerado divino. $\mathrm{El}$ término «Jugar a ser Dios»" también es utilizado por quienes se oponen a los avances de la ciencia, al referirse a los pacientes moribundos que pasaron a tomar decisiones y asumir responsabilidades respecto de su vida, actos que no acontecían en el pasado, pues tal actitud quedaba restricta a los designios de Dios.

En este contexto, surge el cuestionamiento sobre cómo podríamos entender y explicar qué ocurrió para que de esta estabilidad moral nosotros pasáramos a una inseguridad o inestabilidad moral.Dworkin afirma que para intentar responder a estas cuestiones debemos tener en cuenta las diversas consecuencias de la biotecnología moderna y la 'estructura general' de nuestra experiencia moral y ética, en la medida en que la ingeniería genética provocó una profunda modificación en el límite entre 'lo que nos es dado naturalmente' y 'aquello por lo que somos responsables'.

La hipótesis de Dworkin se basa en el hecho de que la ciencia genética, el progreso de las ciencias y de las técnicas, que otorgan a los hombres un

4 Como ya había afirmado Leibniz, comparando el hombre con Dios: «siendo cada Espíritu como una pequeña Divinidad en su ámbito»(1981, p. 148). poder cada vez mayor sobre el curso (natural) de las cosas, multiplicaron los problemas éticos, a través de un dislocamiento que altera el límite entre la suerte y la elección que estructura todos nuestros valores $y$, tal dislocamiento, argumenta que «nuestras convicciones morales tradicionales resultarán socavadas» (2003, p. 490).

En función de esta amenaza, nos encontramos aprensivos $e$ inseguros en cuanto a nuestras convicciones morales arraigadas en la tradición ética occidental. La inseguridad moral actual en cuanto a las cuestiones suscitadas por la biotecnología moderna sería, para Dworkin, la sensación de que muchas de nuestras convicciones morales vengan a ser solapadas $y$, de esta forma, vengamos a sufrir «en una especie de caída moral libre» (2003, p. 490), donde tengamos que pensar sobre nuevos dilemas morales teniendo un nuevo telón de fondo y con resultados inciertos, bien como sobre nuevas cuestiones éticas que nunca habían sido pensadas por el género humano. La expresión «Jugar a ser Dios» utilizada por Dworkin, puede ser interpretada en el sentido de que cuanto más somos o pensamos ser «los maestros y poseedores de la naturaleza», según la fórmula profética de Descartes ${ }^{5}$ (y sabemos que Descartes esperaba todo de la medicina del futuro), recurriendo a técnicas innovadoras y audaces, más se ejerce una libertad que nos aparece ilimitada.

De la misma forma que Dworkin, Habermas sostiene que estas innovaciones y modificaciones en técnicas genéticas son capaces de alterar las bases de la experiencia moral de la sociedad. La técnica genética hará que frente a las cuestiones prácticas, surjan dilemas de juicios y cuestiones morales. Argumenta Habermas, que el dislocamiento entre el azar y la libre

5 La medicina era uno de los dominios del conocimiento que Descartes identificaba como uno de los más promisorios para el futuro de la naturaleza humana: [...] on en peut trouver une pratique, par laquelle, connoissant la force et les actions du feu, de l'eau, de l'air [...] et ainsi nous rendre comme maîtres et possesseurs de la nature (Descartes 1952, p. 169). 
decisión afectan la auto comprensión de las personas, que son orientadas por la moral y están preocupadas con la propia existencia.

Ese dislocamiento concientiza a las personas de las relaciones entre la auto comprensión moral y el interior de la ética de la especie. Conforme al autor (2002, p. 40), esa estructura está sintonizada con la forma comol nosotros somos vistos en tanto que seres de la misma especie y por el modo en que seamos responsables por nuestra trayectoria de vida. Como nos explica Habermas, esta profunda modificación de la estructura general de nuestras convicciones normativas modernas se debe a lo que él llama «ampliación de contingencia»: Esta «ampliación de contingencia» que concierne a la naturaleza «interior» se distingue de similares ampliaciones de nuestro espacio de opciones por el hecho de que «modifica la estructura entera de nuestra experiencia moral» (2002, p. 44).

\section{DISLOCAMIENTO MORAL Y AMPLIACIÓN DE LA CONTINGENCIA.}

¿Cómo podríamos comprender esta idea que Dworkin denomina «dislocamiento moral» entre el azar y elección o, como Habermas denomina, la «ampliación de contingencia»? Para tratar de responder a esta cuestión sobre la diferencia fundamental entre el grado de responsabilidad del agente en sus acciones y aquello que nos es dado como telón de fondo de nuestro actuar, Dworkin nos propone la siguiente clasificación: «Se diferencia entre lo que la naturaleza, evolución incluida, (...) ha creado y lo que nosotros hacemos en el mundo con la ayuda de estos genes» (2003, p. 470).

Podríamos simplificar de la siguiente manera: Dworkin indica que tenemos, de un lado, los seres de la naturaleza que, en sí mismos, tienen un cierto principio $y$, de otro, lo que sobre eso hacemos o deliberamos, con una tenue línea divisoria. Lo que él resume como: «El límite capital entre azar y elección», esto es, el límite entre lo que no se puede deliberar (lo que es por naturaleza o por azar) y lo que está sujeto a modificación y deliberación (elección).

En la Ética Nicomáquea de Aristóteles hay una enumeración muy similar a la de Dworkin. A la pregunta acerca de si podemos deliberar sobre todo, Aristóteles $\left(2002,1112^{\mathrm{a}}\right.$, p. 17-18) responde que las cosas respecto de las cuales se puede elegir o deliberar son bien restringidas. Él parte de una prueba negativa estableciendo que nadie delibera sobre lo necesario. Afirma, además, que no deliberamos sobre aquello que es imposible, pues, nadie, por la misma razón, puede elegir lo imposible (como por ejemplo tornarse inmortal). $\mathrm{Ni}$ deliberamos tampoco sobre las cosas de la naturaleza (tales como las estaciones del año) o sobre aquello que, aunque no sea necesario, ocurre la mayoría de las veces, lo más frecuente, por ejemplo, una buena cosecha.

Por último, no deliberamos sobre aquellas cosas que acontecen por azar. En fin, dirá Aristóteles, solamente deliberamos sobre aquello que tanto puede venir a ser de un modo como de otro, esto es, aquello que es contingente con respecto al futuro, incubiéndole al hombre determinar lo que será a través de su elección (2002, p. 1140a29-b3).

Al contrario de todas las demás hipótesis, apenas deliberamos acerca de las cosas que pueden ser realizadas por nuestros propios esfuerzos y que dependen de nosotros para su realización o no. La deliberación ocurre, entonces, en aquellas situaciones de acción donde no siempre se obtiene el mismo resultado actuando de la misma manera en razón de las innumerables variables, exigiendo del agente atención a las circunstancias concretas del caso con que se enfrenta. El ejemplo referido por Aristóteles para ilustrar esta situación es el del médico (2002, p.1112b1-10), pues aunque los síntomas de sus pacientes sean semejantes, él no puede indicar el mismo tratamiento para todos, toda vez que se hace necesario ponderar acerca de todas las particularidades de cada organismo. 
En este punto, estamos en condiciones de comprender cuál es el sentido de la expresión «ampliación de la contingencia» o "dislocamiento moral entre el azar y elección". Como se mencionó anteriormente, sobre las cosas que acontecen por azar nosotros no deliberamos, solo podemos deliberar sobre aquello que está en nuestro poder. Cuando explicábamos la ocurrencia de un evento cualquiera, como por azar (o debido a la propia naturaleza creada por Dios o por el evolucionismo), la ocurrencia de este evento escapaba a nuestro poder de decisión.

A partir del momento en que avanzamos nuestro conocimiento acerca de las causas del evento sobre el cual nosotros no decidíamos y, sobre el cual hoy en día, pasamos a decidir, constatamos el aumento de nuestro poder de decisión y elección, de este modo, aumentamos el espacio de la contingencia del actuar humano. Avanzamos así en nuestro conocimiento y conseguimos adecuarlo al sentido de las verdaderas causas de aquello que, o desconocíamos (no sabíamos la verdadera naturaleza del fenómeno), o atribuíamos la existencia del fenómeno a un encuentro arbitrario de varias causas (sería únicamente fruto del azar).

Esta argumentación puede ser ilustrada a través de la siguiente situación: a causa del color de los ojos, antes del adviento de la genética, era atribuida al azar (a la naturaleza o a la providencia divina) y hoy, los genetistas saben muy bien cuál es la causa, o mejor dicho, cual es el gen responsable del color de los ojos. Esta causa genética es (hoy) tan conocida por los genetistas que es posible interferir y deliberar sobre el color de los ojos. Es perfectamente asequible (tal vez no del punto de vista ético), hoy en día, a una pareja que elija junto a su genetista, cuál será el color de los ojos de su bebé o diversas otras características, tales como altura, color de piel y cabello, bien como en relación a sus talentos.

A comienzos del siglo XX, los científicos no sabían determinar cuáles eran los verdaderos valores acerca de las proposiciones sobre el color de los ojos. Con los descubrimientos de la ingeniería genética pasaron a dominar y deliberar sobre este saber. Es decir, la biogenética está tornando disponible aquello que era, hasta entonces, indisponible. Es a ese tipo de situación que Habermas y Dworkin se refieren al afirmar que hubo este "dislocamiento moral» entre el azar y elección y la concomitante «ampliación de la contingencia»: aquello que era considerado un evento meramente casual o fortuito de la naturaleza, se reveló un evento que posee una causa $y$, arriba de todo, causa ésta la cual no sólo tenemos acceso, pero podemos sobre ella interferir, deliberar o elegir. Dicho de otro modo, el aumento de la contingencia acarrea una ampliación del ámbito de la deliberación y elección moral. O sea, aquello que antes era tenido como "natural", hoy es perfectamente pasible de interferencia humana, para el bien o para el mal.

Sin embargo, debemos hacer una distinción crucial entre este tipo de deliberación que se verifica en el actuar humano y la deliberación técnica. Esta última encuentra en la técnica utilizada por el médico, un buen ejemplo ${ }^{6}$. Pero, ¿cuál es la diferencia entre estos dos tipos de deliberación? Para que podamos comprender esta distinción, veamos en Aristóteles qué existe de similar entre estas dos deliberaciones y en qué ellas difieren.

\section{LA DISTINCIÓN ARISTOTÉLICA ENTRE DELIBERACIÓN TÉCNICA Y LA DELIBERACIÓN ÉTICO-MORAL.}

Cuando en la Ética Nicomáquea Aristóteles describe lógicamente el tipo de raciocinio práctico involucradoen la deliberación, él noestá pensando solamente en la ética, también hace un paralelo con la técnica, especialmente la medicina y la navegación, que funcionaban como paradigmas para explicar la acción humana. En toda la teoría de la deliberación sobre la toma de decisión en casos y situaciones de incertidumbre, Aristóteles

6 A pesar de ser distintos, vamos a tomar como equivalentes el actuar del médico y el del genetista. 
echaba mano de esa comparación, entre la deliberación moral [la deliberación propiamente práctica] y la deliberación técnica. Al introducir la noción de deliberación en las primeras frases de la Ética Nicomáquea (2002, p. 1112b1), él lo hace justamente mediante esa comparación entre la acción práctica y la técnica o el arte. Para explicar en qué consiste la deliberación, el ejemplo que Aristóteles provee es el ejemplo del médico (2002, p. 1112b1-10).

En otro pasaje, Aristóteles (2002, p. 11-14) nos presenta la siguiente situación: «Es evidente que el médico ni siquiera considera así la salud, sino la salud del hombre, y más bien probablemente la de este hombre, ya que cura a cada individuo».

El autor defiende que la salud es el conocimiento que está en el alma del médico. En este punto, el estagirita propone la siguiente indagación: ¿cuál es el significado de la afirmación de que el hombre saludable sería el resultado de la deliberación del médico? Él establece la siguiente respuesta en la forma silogística: dado que $\mathrm{X}$ es salud, para que un paciente cualquiera sea saludable, $\mathrm{X}$ debe estar presente.

Igualmente lo hace aplicando este raciocinio, donde el estado de equilibrio del cuerpo representa la salud, para que esto esté presente, es necesario calor. El médico remonta así progresivamente por el pensamiento hasta una etapa final, según la cual está en su poder producir calor. Su deseo de curar el paciente es el punto de partida de su deliberación. Para que él pueda restablecer la salud del paciente es necesario producir calor en el cuerpo del paciente. Vamos a suponer que el médico sepa que hay mantas que están a su alcance. En este caso, dice Aristóteles ${ }^{7}\left(701^{a} 17-22\right)$, el médico piensa: «tengo

7 En el tratado Mouvement des animaux Aristóteles nos proporciona más informaciones sobre el proceso de deliberación. La acción representa la conclusión de una deliberación. En el caso del hombre, la imagen del silogismo llamado «práctico» puede ayudarnos a comprender cómo sería una deliberación. Tomemos el ejemplo del pasaje 701a17-22 del tratado Movimento necesidad de cubrir [me]; ora una manta sirve para cubrir; tengo necesidad de una manta». Conclusión: el médico toma inmediatamente las mantas para cubrir el paciente. La conclusión de este silogismo representa la acción a ser realizada: cubrir el paciente, calentándolo para restablecer la salud.

En fin, Aristóteles utiliza como recurso el ejemplo del médico para ilustrarnos cómo se opera la deliberación. Los médicos de la época de Hipócrates y de Aristóteles, como los médicos actuales, con el nivel de conocimiento del Siglo XXI, deliberan usando unos procedimientos deliberativos muy semejantes a los que un agente moral o un agente político utilizan.

¿Qué quiere realmente decir Aristóteles al afirmar que los médicos deliberan? ¿Por qué los médicos simplemente no utilizan procedimientos mecánicos para decidir qué hacer en relación a un paciente determinado? Por una razón muy simple: porque no se posee un conocimiento, una ciencia, de las diferentes enfermedades. Lo que tenemos es, de un lado, la técnica médica y, de otro, la ciencia de la biología. Esta última, compuesta de enunciados universales que dicen que tales factores son causas de tal o cual enfermedad; tales síntomas son indicios de tal o cual enfermedad.

Pero, lo que no existe es una relación deductiva entre esos enunciados universales, que los médicos aprenden en la facultad de Medicina, y el caso singular del paciente. ¿Aquellos síntomas que tal paciente presenta son síntomas de qué? Esto es, el médico, en esta etapa, aún no está interesado en saber cuál es la relación causal entre aquellos síntomas de su paciente y eventualmente tal o cual procedimiento médico, tales como quimioterapia, radioterapia, etc. La

dos Animais: «tengo necesidad de cubrirme; ora una manta sirve para cubrir; tengo necesidad de una manta. Esto de lo cual tengo necesidad, es necesario que yo lo haga; tengo necesidad de una manta; es necesario entonces hacer una manta». La conclusión de este silogismo representa la acción a ser realizada, el objeto deseado. 
primera cosa que el médico tiene que hacer es identificar aquellos síntomas de esto o aquello, es decir, tal o cual enfermedad.

Acto seguido, el médico pasa a la deliberación de naturaleza causal, esto es, a identificar las causas de la enfermedad y a buscar su posible cura. Tenemos en forma análoga la deliberación del juez, el cual debe aplicar la ley y evaluar todas las peculiaridades de las circunstancias del caso concreto para decidir cómo se dará la mejor adecuación de la ley al caso. Deberá el juez ponderar cuál es la mejor manera de aplicar la ley, así como el médico deberá evaluar cómo obtener la cura del paciente.

No obstante, a pesar de esa similitud, de ese parentesco, hay una diferencia lógica entre la deliberación técnica (técnica médica) y la deliberación de la justicia política (en la acción humana). En el caso de la deliberación judicial (del juez) existe un aspecto ontológico intransferible de la contingencia del caso concreto y de los varios aspectos circunstanciales relevantes que pueden ocurrir y que impiden que esta deliberación se limite apenas al análisis universal y abstracto de la ley.

El juez ecuánime delibera a partir de las circunstancias y consigue así reubicar la ley en su singularidad. Este juez «no es otro sino el hombre justo y prudente, aquél que toma las decisiones en función e inmerso en la particularidad de cada acción» (Zingano, 2007, p. 348.). Según Zingano, existe esa indeterminación en el campo de las acciones que es antes ontológica que epistémica, o sea, es una indeterminación de la propia acción como tal y no de un problema de mayor o menor conocimiento de las variables involucradas.

Es en función de una oscuridad epistemológica que el médico desconoce la multiplicidad de variables afectadas en la aplicación de aquel saber de la biología al individuo X en concreto. Esta indeterminación de la medicina como técnica es una indeterminación epistémica, al nivel del conocimiento o falta de este.
Cuanto más el médico conoce, menos delibera en su técnica médica en relación con el paciente. De esta forma, lo que diferencia esta deliberación (del médico, como médico) de la deliberación judicial (moral) es que en esta última, la indeterminación no es una cuestión de conocimiento pero, como dice Aristóteles, es una indeterminación con relación a la materia de las acciones humanas que afecta las acciones: la contingencia ontológica.

El argumento del Estagirita es que, como la contingencia en el dominio técnico es esencialmente una contingencia epistémica, ella, en principio, podrá ser eliminada o, por lo menos, disminuida. ${ }^{8}$

¿Cómo podemos comprender por qué la medicina, como una técnica, posee una deliberación precaria y que depende del carácter desconocido de determinadas enfermedades? Del mismo modo, como vimos anteriormente, en la medida en que esta oscuridad desaparece, disminuye también la deliberación del médico. En la ética Nicomáquea, con efecto, Aristóteles excluye la deliberación de las «ciencias» (2002, p. 112b1-5), pero incluye técnicas como la navegación y la medicina, cuyos resultados no son siempre los mismos y depende de nosotros su realización.

En otra de sus obras, denominada Ética Eudemia (1997, p. 1226a35), sin embargo, Aristóteles cuestiona por qué los médicos deliberan sobre aquello que ellos tienen ciencia, pero no los gramáticos. La razón ofrecida es que hay un doble error en la medicina (en el raciocinio y en la percepción al aplicar los resultados de la deliberación), mientras, en la gramática hay un único tipo de error (el de la percepción). El

8 Esto no significa que Aristóteles esté afirmando, como hizo Descartes (cf. nota 10) que eso fatalmente ocurrirá. Lo que Aristóteles está diciendo es que si la contingencia en el dominio técnico es esencialmente epistémica, entonces, en principio, desde el punto de vista puramente lógico, no hay ningún obstáculo en la posibilidad de la eliminación de la contingencia epistémica. 
punto aquí es que en el caso de la medicina, el error pudiendo ser, de un lado, la determinación de las causas de una determinada enfermedad $y$, de otro, la aplicación de estos resultados a un paciente en concreto, la medicina siempre involucraría alguna indeterminación de cómo proceder. Siempre queda algo obscuro e indefinido dice Aristóteles al afirmar que « (...)la deliberación dice respecto a aquellas cosas que, produciéndose en un buen número de casos, permanecen inciertos en su realización, y en las cuales es indeterminado» (2002, p. 1112b8-10).

\section{CONCLUSIÓN}

Lo que resulta claro y cabe en esta instancia concluir es que las decisiones en este campo transcienden el plano meramente técnico. Es una discusión relativaa los principales actores de esta escena: desde el médico, con su deliberación técnica, hasta el paciente, con su deliberación moral.

En este contexto, podemos comprender esta afirmación con la idea de una «ampliación de la contingencia» a través del advenimiento de las técnicas modernas. Lo que puede disminuir es la contingencia de la técnica médica que, como técnica, depende de una cuestión epistemológica del conocimiento. Cuanto más el médico tiene su conocimiento como una ciencia y utiliza procedimientos mecánicos para decidir qué hacer en relación a un paciente determinado, menos libertad él tendrá como médico.

No se verifica lo mismo en el caso del agente moral o del juez, pues las circunstancias de las acciones imponen al agente moral siempre una variabilidad, así como en el caso del juez, donde la ley permite una amplia variedad de interpretaciones $y$ donde es imposible una transmisión mecánica entre la ley universal y el caso particular. Al contrario del médico, en el caso del agente moral, lo que aumenta es la deliberación moral (o judicial) de la acción, pues, como vimos, ese tipo de indeterminación de los asuntos prácticos no es una indeterminación de orden epistémica, o sea, su indeterminación no es minimizada por el progreso o acumulación de conocimiento, pero lo que se amplía es el campo de aplicación de nuestro actuar delante de problemas que antes eran tenidos como inevitables, naturales o por azar y que ahora cabrá al agente moral (el paciente, un familiar o el propio juez) deliberar moralmente sobre el caso y al agente técnico (el médico que va a concretar la acción) en su deliberación técnica.

Esta contingencia ahora no es más que una deliberación meramente técnica, pero es principalmente una deliberación moral: el agente al deliberar cuando va a desconectar un aparato que soporta un paciente terminal; decidir el sexo y el color de los ojos del bebé, decidir si va o no a destruir un embrión para remover células-tronco para su utilización en nuevos experimentos afectando nuevos tratamientos, etc., son todas deliberaciones morales que ampliaron la libertad y el actuar humano y que deben ser tratadas como cuestiones no meramente de orden técnico, pero, al contrario, deben ser correctamente comprendidas como deliberaciones morales-judiciales y, como tales, deben ser enfrentadas. Por eso, en este tipo de deliberación quien debe proferir la decisión no puede ser aquél que delibera de forma técnica meramente ${ }^{9}$ (como el médico o el genetista, por ejemplo), pero debe ser una deliberación política-jurídica involucrada en la acción a través del paciente, de la familia del paciente o, en última instancia, del legislador y/o el juez. Deberíamos tomar como idea reguladora la salud. Nadie tiene el derecho de decidir a partir de sus propias preferencias sobre la distribución de fuentes naturales para la vida de una $\mathrm{u}$ otra persona. Una intervención genética debe tener por principio el asentimiento potencial de la persona que está por nacer. El modelo

9 En las cuestiones del ejercicio de la profesión de médico, los consejos de medicina tienen un papel fundamental en la fijación de las directrices de la bioética. Pero al establecer estos marcos éticos del profesional de la medicina, los médicos lo hacen no como médicos, sino como agentes morales, como ciudadanos. 
de médico que cuida del paciente de forma eugénica ocupa este lugar como si fuera un designer que hace ensayos, planes; o como si fuera ingeniero, realiza meros cálculos y aplicaciones de fórmulas.

Es necesario que el legislador democrático establezca la lista de intervenciones autorizadas, ponderando cuidadosamente los pros y los contras. En este punto, podemos volver a leer las afirmaciones de Dworkin y Habermas acerca del dislocamiento moral y aumento de la contingencia bajo la mirada de Aristóteles: lo que Aristóteles nos recuerda todo el tiempo es que las decisiones acerca de los problemas de la ética o de la bioética no se refieren exclusivamente a los avances de la técnica de la medicina como tal. O sea, por más que la medicina evolucione y que los médicos tengan un amplio saber sobre el cuerpo humano y sus propiedades esenciales, las cuestiones acerca de las decisiones y elecciones a tomar por los agentes morales (como pacientes o jueces) conciernen a la deliberación política-jurídica. Se abre, así, un nuevo campo de cuestiones morales y jurídicas que antes no se planteaban por el simple hecho de que no existían las condiciones fácticas para su formulación. ${ }^{10}$ Tenemos así, en este retroceso de la línea demarcatoria entre lo que era «natural» y que ahora pasamos a intervenir, un espacio cenagoso que podríamos denominar de nido de cuestiones que alimentarán los problemas ético - jurídicos del siglo XXI.

10 Algo similar podría ser pensado con la cuestión del medio ambiente. Aristóteles escribió diversos tratados sobre la relación del hombre con los demás animales. Sin embargo, él no se pregunta sobre la extinción de animales o sobre la contaminación del medio ambiente. Aristóteles valoraba fuertemente el estudio de los animales en relación con los seres divinos, como nos recuerda Labarrière (2005, p. 228), al afirmar que él, citando Heráclito, decía: «Entrez, il y a des dieux aussi dans la cuisine». De este modo, Aristóteles nos invita a ver desde cerca cómo se estudia la naturaleza y cómo ella funciona. Pero es claro que en este estudio no aparece el problema de la destrucción y aniquilación de los medios de subsistencia del planeta y su completa contaminación. Estos problemas relativos al medio ambiente solamente surgirán con la revolución industrial.

\section{REFERENCIAS}

Aristóteles. (2002). Ética a Nicómaco. 8 ed. Madrid: Centro de Estudios Políticos y Constitucionales.

Aristóteles (1997), Éthique à Eudème, traduction de Vianney Décarie, Paris, Editorial: Librairie Philosophique Vrin.

Aristóteles. (1973). Mouvement des animaux, texte établi et traduit par P. Louis. Paris : Les Belles Lettres.

Ballesteros, J. (2001). Manual de bioética. Barcelona: Editorial Ariel S.A.

Beauchamp, T \& Childress, J., (1.979). Principio de Ética Médica. USA: Masson.

Descartes, R. (1952). Discours de la méthode, $6^{\text {ème }}$ partie, CEuvres et Lettres. Paris : Gallimard.

Dworkin, R. (2003). Virtud soberana. Barcelona: Paidós.

Engelhardt, T. (2003). Pluralismo moral e metafísico. Repensar a santidade da vida e da dignidade humanas. InGarrafa, V. \& Pessini, L. (Org.). Bioética: poder e injustiça. São Paulo: Loyola.

Habermas, J. (2002). El futuro de la naturaleza humana. ¿Hacia una eugenesia liberal? Barcelona: Paidós.

Labarriere, J. L. (2005). La condition animale: études sur Aristote et les stoïciens. Louvain-LaNeuve :Éditions Peeters.

Legendre, P. (1985). Linestimable objet de la transgression, étude sur le principe généalogique en Occident. Paris : Fayard.

Leibniz, G. (1981). Monadología. Traducción Velarde, J. Oviedo: Pentalfa Ediciones.

Rott, P. (1979). Bioethics and society. Constructing the Ethical enterprise. Miami: SL Olaf College, University of Miami. 
Sandel, M. (2013). Contra A Perfeição - Ética na Era da Engenharia Genética. Rio de Janeiro: Civilização Brasileira, Rio de Janeiro,

Zingano, M. (2007). Estudos de Ética Antiga. São Paulo: Discurso Editorial.
Informe BELMONT (1979). Principio y guías éticos para la protección de los sujetos humanos de investigación. Comisión nacional para la protección de los sujetos humanos de investigación biomédica y del comportamiento. USA: Observatori de ética i dret. Parccientific de Barcelona. 